\title{
Transcriptional regulation of cholesterol and bile acid metabolism after dietary soyabean meal treatment in Atlantic salmon (Salmo salar L.)
}

\author{
Trond M. Kortner*, Jinni Gu, Åshild Krogdahl and Anne Marie Bakke \\ Department of Basic Sciences and Aquatic Medicine, Aquaculture Protein Centre (a CoE), \\ Norwegian School of Veterinary Science, PO Box 8146 Dep, NO-0033 Oslo, Norway \\ (Submitted 11 January 2012 - Final revision received 20 April 2012 - Accepted 22 April 2012 - First published online 30 May 2012)
}

\section{Abstract}

Inclusion of plant protein sources such as soyabean meal (SBM) in aquafeeds is associated with decreased lipid digestibility, reduced bile acid levels and hypocholesterolaemia. The mechanism for these metabolic abnormalities is unknown. The present study aimed at gaining further insight into how cholesterol and bile acid metabolism is modulated by SBM feeding by quantifying a number of mRNA species corresponding to key proteins involved in cholesterol and bile acid metabolism using quantitative real-time PCR. A $21 \mathrm{~d}$ feeding trial with sequential sampling at ten time points following initiation of $20 \%$ SBM exposure was conducted on Atlantic salmon. A histological evaluation confirmed distal intestinal enteritis after $5 \mathrm{~d}$ of dietary exposure to the SBM, whereas diminished glycogen/lipid deposition was the only relevant finding observed in the liver. SBM inclusion resulted in reduced body pools of cholesterol and bile acids. Hepatic gene expression profiles revealed up-regulation of genes encoding rate-limiting enzymes in cholesterol (3-hydroxy-3-methyl-glutaryl-CoA reductase; HMGCR) and bile acid (cytochrome P4507A1 (CYP7A1)) biosynthesis, as well as up-regulation of their associated transcription factors (sterol regulatory element binding proteins 1 and 2, liver X receptor, farnesoid X receptor and PPAR isoforms). Hepatic gene expressions of cholesterol (ATP binding cassette G5 (ABCG5)) and bile acid (ATP binding cassette B11 (ABCB11)) transporters were, by and large, not influenced by the SBM, but distal intestinal expression patterns of ABCG5 and apical Na-dependent bile acid transporter indicated impaired cholesterol and bile acid reabsorption. In conclusion, hepatic gene expression profiles indicated that the capacity for cholesterol and bile acid synthesis was up-regulated, whereas the indicated impaired cholesterol and bile acid reabsorption probably occurred as a direct result of distal intestinal inflammation.

\section{Key words: Cholesterol: Bile acids: Soyabean meal: Quantitative real-time PCR}

Continued growth in the aquaculture industry will be dependent on alternative plant protein ingredients to replace traditionally used marine sources such as fishmeal (FM) and fish oil. Soyabean meal (SBM) has been considered a candidate plant product for increased use in aquafeeds due to its moderate price, good availability and reasonably balanced amino acid profile ${ }^{(1)}$. Inclusion of full-fat and extracted (defatted) SBM in aquafeeds is, however, limited since a number of negative effects are observed. Besides the welldocumented intestinal inflammation in salmonids ${ }^{(2-4)}$ and carp $^{(5)}$, SBM inclusion in fish feed has been associated with decreased lipid digestibility, reduced bile acid levels and hypocholesterolaemia $^{(6-12)}$. A hypocholesterolaemic effect, often accompanied by decreased bile acid levels and reduced fish performance, is not restricted to SBM inclusion solely, but has been observed after inclusion of many plant protein sources in a wide range of teleost species ${ }^{(13-18)}$. Presently, it is unknown which plant component(s) are responsible for modulations in sterol metabolism and their molecular mechanisms have not been specifically investigated.

Bile acids are physico-chemical detergents and play a key role in the digestion and absorption of lipids, fat-soluble vitamins and other apolar components in the diet or from endogenous sources ${ }^{(19)}$. They are synthesised in the liver from the precursor cholesterol, conjugated with glycine or taurine, and are released into the gut upon ingestion of a meal. The proportion between conjugated (often called bile salts) and unconjugated bile acids may vary between different body compartments. The term bile acid is used consistently throughout the present study for the sum of free and conjugated bile acids. In addition to hepatic de novo synthesis, almost all bile acids in warm-blooded animals undergo an enterohepatic circulation, where they are reabsorbed in the intestine, transported back to the liver via the portal system

\footnotetext{
Abbreviations: ABCG5, ATP binding cassette G5; ABCB11, ATP binding cassette B11; ACTB, $\beta$-actin; ASBT, apical Na-dependent bile acid transporter; DI, distal intestine; FM, fishmeal; FXR, farnesoid X receptor; HMGCR, 3-hydroxy-3-methyl-glutaryl-CoA reductase; LXR, liver X receptor; PCNA, proliferating cell nuclear antigen; PI, pyloric intestine; qPCR, quantitative real-time PCR; SBM, soyabean meal; SREBP, sterol regulatory element binding protein.
} 
and finally re-secreted into the bile ${ }^{(20)}$. From mammalian studies, it is clear that bile acids have many functions other than as emulsifiers and excretable waste products of cholesterol metabolism ${ }^{(21)}$. They increase protein hydrolysis and modulate mucus secretion as well as fluid and electrolyte absorption $^{(19)}$. Information is emerging that bile acids have important anti-inflammatory effects in the gut and liver ${ }^{(22)}$. They also have antimicrobial effects ${ }^{(23,24)}$, and a cancerpreventive role has been suggested ${ }^{(25-28)}$. Bile acids are potentially cytotoxic and therefore their concentration in different body compartments is tightly controlled by a sophisticated network of nuclear receptors ${ }^{(29)}$.

Cholesterol can be obtained from the diet or synthesised de novo in the liver, and the conversion of cholesterol to bile acids represents a major route for the elimination of cholesterol from the body. Consequently, cholesterol and bile acid metabolism are closely linked, and are controlled and balanced by nuclear receptors such as the liver X receptor (LXR) and the farnesoid X receptor $(\mathrm{FXR})^{(30)}$. The decreased body pools of cholesterol and bile acids observed with dietary SBM inclusion may be a result of any one or several of the following factors: (1) increased faecal excretion; (2) impaired intestinal reabsorption; (3) impaired transport between body compartments; and/or (4) impaired hepatic biosynthesis. It is well known that SBM contains several anti-nutrients which may exert nutritional, physiological and immunological actions ${ }^{(31,32)}$. For example, soya isoflavones may activate nuclear receptors such as LXR, FXR and PPAR isoforms, and consequently modulate sterol and bile acid metabolism ${ }^{33)}$. Soya isoflavones can also affect sterol regulatory element binding proteins (SREBP) and SREBP-regulated genes ${ }^{(34)}$. Another group of soya anti-nutrients are saponins, which generally have a hypocholesterolaemic action $^{(35)}$. This has been attributed to the observation that most saponins can form complexes with 3 - $\beta$-hydroxysteroids such as bile acids and cholesterol ${ }^{(36)}$, and thereby prevent their absorption in the intestine. Additionally, soyabeans are rich in lectins, which may modulate the proliferation of various mucosal cells and consequently affect the regulation of transport, intestinal hormone release and nutrient metabolism ${ }^{(31)}$. Most probably, interactions between different anti-nutrients are responsible for the altered intestinal physiology and lipid metabolism, but information on these interactions is scarce.

The present study aimed at gaining further insight into how cholesterol and bile acid metabolism are modulated by SBM inclusion in salmon feed. A $21 \mathrm{~d}$ feeding trial with sequential sampling at ten time points following initiation of $20 \%$ SBM exposure was conducted on Atlantic salmon (Salmo salar). A number of mRNA species in the liver and distal intestine (DI) corresponding to key proteins involved in cholesterol and bile acid metabolism were quantified using quantitative real-time PCR (qPCR). Specifically, we quantified the expression of the rate-limiting enzymes in cholesterol and bile acid synthesis (3-hydroxy-3-methyl-glutaryl-CoA reductase, HMGCR and cytochrome P4507A1, CYP7A1, respectively), the cholesterol transporter ATP binding cassette G5 (ABCG5) and the bile acid transporters ABCB11 and apical Na-dependent bile acid transporter (ASBT, gene symbol SLC1OA2), as well as transcription factors which are known to play key regulatory roles in lipid metabolism (SREBP-1 and -2, LXR, FXR and PPAR isoforms). Tissues of interest were liver, which is the main organ for cholesterol and bile acid synthesis, and the DI, which is presumably responsible for bile acid reabsorption, but whose function may be compromised due to SBM-induced enteropathy. Total bile acid levels in the plasma, liver and intestinal content, as well as plasma cholesterol levels were measured. Histomorphological alterations in the liver and DI after inclusion of SBM in the diet were evaluated.

\section{Materials and methods}

\section{Experimental animals, diet and sampling}

The experiment was conducted in accordance with laws and regulations that control experiments and procedures in live animals in Norway, as overseen by the Norwegian Animal Research Authority. The experiment was performed at Nofima Marine's (formerly AKVAFORSK - Institute of Aquaculture Research) research station at Sunndalsøra (Norway). Details on fish husbandry and sampling procedure can be found elsewhere ${ }^{(37)}$. Briefly, farmed Atlantic salmon (Salmo salar L.) with an initial body weight of 500-600 g were stocked in fibreglass tanks ( $1 \mathrm{~m}^{3}, 25-30$ fish per tank) containing running seawater with a temperature of $8-10^{\circ} \mathrm{C}$. After distribution to the tanks, a $7 \mathrm{~d}$ adaptation period was allowed, during which the fish were fed the reference FM diet (Table 1). The control fish fed the reference FM diet were sampled at day 0 . The exposed fish were fed a diet containing 20\% extracted SBM (Table 1) and sampled after 1, 2, 3, 5, 7, 10, 14, 17 and $21 \mathrm{~d}$. For each time point, two replicate tanks were used. Randomly selected fish were anaesthetised with tricaine methanesulphonate (MS 222; Argent Chemical Laboratories) and subsequently euthanised by cervical dislocation. Only the fish that had digesta throughout the intestinal tract were sampled to ensure intestinal

Table 1. Formulation and analysed chemical composition of fishmeal (FM) and soyabean meal (SBM) diets

\begin{tabular}{|c|c|c|}
\hline Ingredients (g/kg) & FM & SBM \\
\hline Fish meal $^{*}$ & 563 & 435 \\
\hline Soyabean meal (extracted)† & & 200 \\
\hline Fish oilł & 234 & 243 \\
\hline Whole wheat§ & 179 & 98 \\
\hline Vitamin mix\| & 20 & 20 \\
\hline Mineral mix $\|$ & 4 & 4 \\
\hline Yttrium oxideף & $0 \cdot 1$ & 0.1 \\
\hline Carophyll Pink $10 \%$ ** & 0.4 & 0.4 \\
\hline \multicolumn{3}{|l|}{ Chemical composition (\%) } \\
\hline Protein & $42 \cdot 7$ & $42 \cdot 6$ \\
\hline Lipid & $28 \cdot 0$ & $27 \cdot 9$ \\
\hline Carbohydrate & $14 \cdot 2$ & $14 \cdot 8$ \\
\hline Ash & $8 \cdot 8$ & $8 \cdot 1$ \\
\hline Water & $6 \cdot 7$ & $7 \cdot 0$ \\
\hline Energy (MJ gross energy/kg) & 23.7 & 23.8 \\
\hline
\end{tabular}

* NorsEco LT, supplied by Norsildmel.

† Supplied by Felleskjøpet Øst Vest.

$\ddagger$ NorSalmOil, supplied by Norsildmel.

§ Supplied by Norgesmøllene.

\| Supplemented to meet the requirements.

I Marker for evaluation of nutrient digestibility.

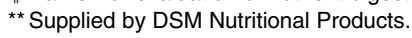


exposure to the SBM. The intestines were cleared of all fatty tissue and intestinal content before collection of tissue samples from the DI. Liver and distal intestinal tissues were sampled from four fish from each tank for mRNA extraction, placed in RNAlater (Ambion) at $4^{\circ} \mathrm{C}$ for $24 \mathrm{~h}$ and then stored at $-20^{\circ} \mathrm{C}$. Liver tissues (three fish per tank) for the measurement of bile acid content were frozen in liquid $\mathrm{N}_{2}$ and then stored at $-80^{\circ} \mathrm{C}$. Blood (three fish per tank) was collected in heparinised vacutainers for plasma preparation. Intestinal contents (three fish per tank, only time points 0, 1, 2, 3, 7, 14 and 21) from the proximal and distal halves of the pyloric intestine (PI1 and PI2), mid-intestine and the proximal and distal halves of the DI (DI1 and DI2) were frozen in liquid $\mathrm{N}_{2}$ and then stored at $-80^{\circ} \mathrm{C}$. Liver and distal intestinal tissues (four to six fish per tank) were sampled for histological evaluation, placed in $4 \%$ phosphate-buffered formaldehyde solution for $24 \mathrm{~h}$ and subsequently stored in $70 \%$ ethanol until further processing.

\section{Primer optimisation}

qPCR primers for amplification of gene-specific PCR products were designed using Primer3 software (http://frodo.wi.mit. edu/primer3/). Published primers were used to quantify the expression levels of SREBP-1 and -2, LXR, HMGCR ${ }^{(38)}$ and $\mathrm{ABCB} 11^{(39)}$. Before $\mathrm{qPCR}$, all primer pairs were used in gradient reactions in order to determine optimal annealing temperatures. The primer details are shown in Table 2. All chosen primer pair concentrations used at the selected annealing temperatures gave a single band pattern for the expected amplicon of interest in all reactions. To verify correct amplification, PCR products were purified and sequenced by Eurofins MWG Operon. All sequences were confirmed using NCBI nucleotide BLAST software (http://blast.ncbi.nlm.nih. gov). PCR efficiency for each gene assay was determined using 2-fold serial dilutions of randomly pooled complementary DNA. To verify isoform-specific amplification of PPAR isoforms, PPAR PCR products were purified and cloned into a $\mathrm{pCR}^{\circledR} 4-\mathrm{TOPO}^{\circledR}$ vector in INV $\alpha \mathrm{F}$ ' Escherichia coli (Invitrogen). Positive clones confirmed by sequencing were used as templates in PCR with all three PPAR primer pairs. Unspecific amplification was not observed.

\section{Quantitative real-time $P C R$}

Total RNA was extracted from liver and DI tissue samples (approximately $50 \mathrm{mg}$ ) and homogenised in Trizol reagent (Gibco-Invitrogen Life Technologies) according to the manufacturer's protocol. The integrity of the RNA samples was verified by the 2100 Bioanalyzer in combination with an RNA Nano Chip (Agilent Technologies). RNA purity and concentrations were measured using the NanoDrop ND-1000 Spectrophotometer (NanoDrop Technologies). Before reverse transcription, total RNA from all samples were subjected to DNase treatment using a TURBO DNA-free kit (Ambion) according to the manufacturer's protocol. First-strand complementary DNA synthesis was performed using $1.0 \mu \mathrm{g}$ total RNA from all samples using Superscript III (Invitrogen), and primed with Oligo(dT)20 primers. Negative controls were

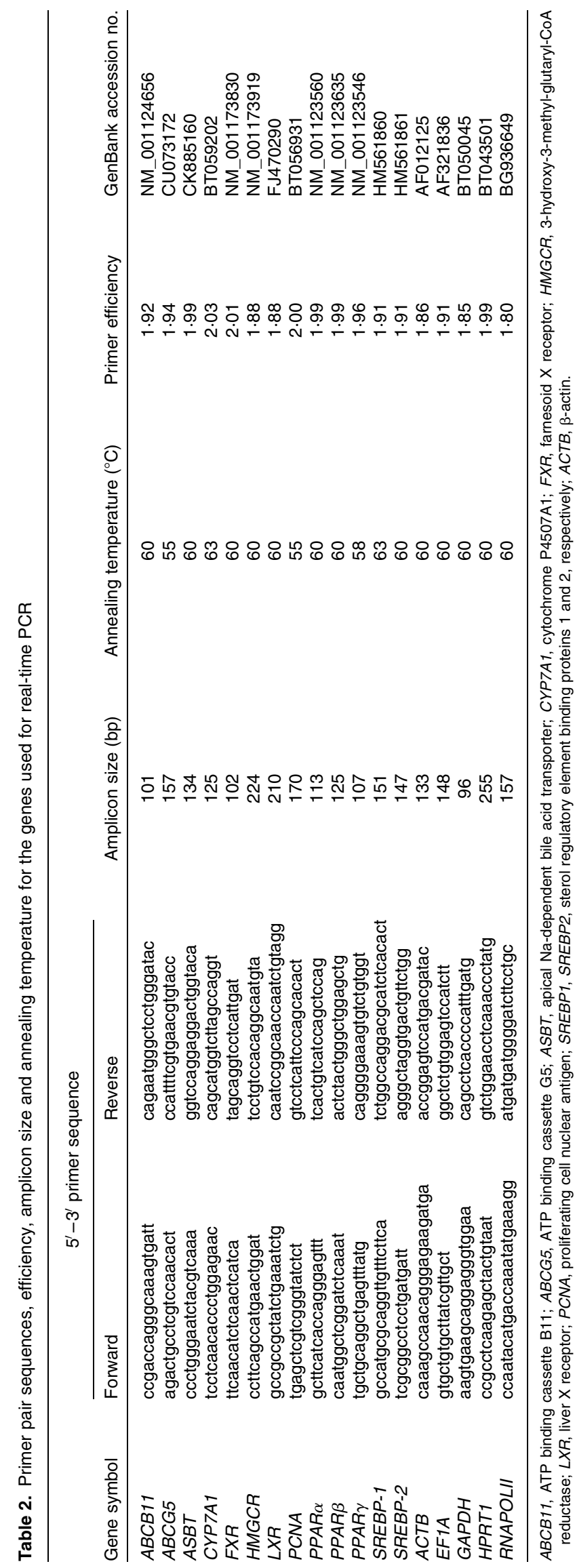


performed in parallel by omitting RNA or enzyme. The expressions of individual gene targets (eight fish per group) were analysed using the LightCycler 480 (Roche Diagnostics). Each $10 \mu \mathrm{l}$ DNA amplification reaction contained 0-2 $\mu$ l PCRgrade water (depending on the template amount), $2-4 \mu \mathrm{l}$ of 1:5 diluted complementary DNA template, $5 \mu$ l LightCycler 480 SYBR Green I Master (Roche Diagnostics) and $0.5 \mu \mathrm{l}$ $(10 \mu \mathrm{M})$ of each forward and reverse primer. Each sample was assayed in duplicates, including a no-template control and an inter-run plate calibrator. The three-step qPCR programme included an enzyme activation step at $95^{\circ} \mathrm{C}(5 \mathrm{~min})$ and forty to forty-five cycles at $95^{\circ} \mathrm{C}(10 \mathrm{~s}), 55-60^{\circ} \mathrm{C}$ (depending on the primers used, $10 \mathrm{~s}$; see Table 2$)$ and $72^{\circ} \mathrm{C}(15 \mathrm{~s})$. Quantification cycle $\left(C_{\mathrm{q}}\right)$ values were calculated using the second derivative method. To confirm amplification specificity, the PCR products from each primer pair were subjected to melting curve analysis and visual inspection of the PCR products was performed after each run by agarose gel electrophoresis. Distal intestinal gene expression was normalised to the geometric average of glyceraldehyde-3-phosphate dehydrogenase $(G A P D H)$, RNA polymerase 2 (RNAPOII) and hypoxanthine phosphoribosyltransferase 1 (HPRT1) expression as evaluated elsewhere ${ }^{(37)}$. For liver samples, $\beta$-actin $(A C T B)$, HPRT1, GAPDH and elongation factor $1 \alpha(E F 1 A)$ were evaluated for use as reference genes by ranking relative gene expression according to their overall $\mathrm{CV}$ and their interspecific variance as described elsewhere ${ }^{(37)}$. The geometric average expression of $G A P D H, A C T B$ and $E F 1 A$ was used as normalisation factor for liver samples. Mean normalised expression of the target genes was calculated from raw $C_{\mathrm{q}}$ values using a plate calibrator-normalised relative quantification ${ }^{(40)}$

\section{Histology}

The histological evaluation of the DI and the progression of SBM-induced enteropathy have been reported elsewhere ${ }^{(37)}$. Liver tissue samples were routinely dehydrated in ethanol, equilibrated in xylene and embedded in paraffin according to the standard histological techniques. The tissue samples were sectioned (approximately $5 \mu \mathrm{m}$ thick), stained with haematoxylin and eosin, and examined by light microscopy.

\section{Cholesterol and bile acid analyses}

Plasma cholesterol and bile acid concentrations, as well as bile acid concentrations in the liver and intestinal content were determined as described previously ${ }^{(12)}$. All analyses were performed automatically (Advia ${ }^{\circledR} 1800$; Siemens Healthcare Diagnostics) at the Central Laboratory of the Norwegian School of Veterinary Science (NVH), Oslo, Norway.

\section{Data analysis}

Statistical analysis was performed using GraphPad Prism, version 5.00 (GraphPad Software, Inc., 2007). Data were assessed for normality and variance homogeneity using the Kolmogorov-Smirnov test and Bartlett's test, respectively. Where necessary, data were transformed to improve the normality of distribution. For qPCR data and cholesterol and bile acid levels, significant differences between the time points were determined by one-way ANOVA followed by Tukey's multiple comparison test. For the histological evaluation of liver samples, results were compared using a $\chi^{2}$ test. Spearman's rank correlation $(\rho)$ test was employed to evaluate the relationship between liver glycogen/lipid deposition levels and DI enteritis severity. Significance was set at $P<0 \cdot 05$.

\section{Results}

\section{Histology}

As presented elsewhere ${ }^{(37)}$, inclusion of SBM in the diet induced histomorphological alterations in the DI similar to those reported previously ${ }^{(2,3)}$ following $5 \mathrm{~d}$ of exposure. The severity increased with increasing exposure time. Liver examination showed that a high level of hepatic glycogen/lipid deposition (four out of eight fish) was more frequently observed in the control (FM-fed; day 0$)$ fish $(P=0.0030)$. The liver samples on days 1 and 3 showed a higher frequency of intermediate levels of glycogen/lipid deposition (seven out of eleven fish and six out of twelve fish, respectively), and glycogen/lipid deposition appeared to decrease further with increasing SBM exposure time (Fig. 1(a) and (b)). Otherwise, the general morphological structure for most livers was normal, with the exception of focal acute hepatic cell injury observed in some fish (fourteen out of 108 fish). The pathological features included focal necrosis, lymphocyte infiltration and ballooning degeneration. No significant differences, however, were observed among the time points. Ductular reaction, which is characterised as the increased number of bile ducts accompanied by cellular proliferation of the surrounding
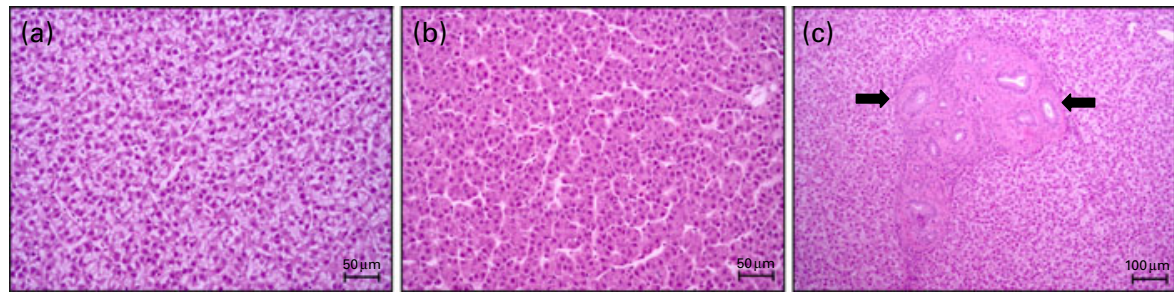

Fig. 1. Hepatic histomorphological evaluation of the experimental fish (haematoxylin and eosin). Representative image of (a) a high level of glycogen/lipid deposition in hepatocytes of fish fed the fishmeal control diet and (b) a very low level of glycogen/lipid deposition in hepatocytes of fish fed the soyabean meal (SBM)based diet for $21 \mathrm{~d}$. (c) Ductular reaction $(\rightarrow)$, an increased number of bile ducts accompanied by proliferation of the surrounding matrix, in the liver of one fish fed the SBM for $21 \mathrm{~d}$. (A colour version of this figure can be found online at www.journals.cambridge.org/bjn). 
matrix (cuffing), was observed in one fish on day 21 (Fig. 1(c)). Interestingly, the liver glycogen/lipid deposition level showed a significant positive correlation with DI enteritis severity $(\rho=0.36, P=0.0002)$.

\section{Cholesterol and bile acid levels}

Cholesterol and bile acid concentrations in the plasma decreased progressively during the feeding trial, resulting in approximately 25 and $90 \%$ reduced levels, respectively, after 14-21 d compared with the control levels (Fig. 2). Bile acid concentrations in the liver showed a similar reduction with SBM treatment (Fig. 2). Also, bile acid concentration in intestinal content was decreased for fish fed the SBM in all segments except DI2, significantly so at days 7, 14 and/or 21 depending on the region (Table 3 ).

\section{Gene expression profiling}

As shown in Fig. 3, SBM inclusion had profound effects on the hepatic expression of key genes involved in cholesterol and bile acid metabolism. Generally, SBM inclusion produced an up-regulation of genes encoding the rate-limiting enzymes in cholesterol and bile acid synthesis (HMGCR and CYP7A1, respectively), as well as up-regulation of their associated transcription factors (SREBP-1, SREBP-2, LXR, FXR, PPAR $\beta$ and $P P A R \gamma$ ). Some genes, such as $L X R$ and $A B C G 5$, seemed to respond at earlier time points, whereas the majority of the target genes displayed mRNA levels which increased, more or less steadily, during the experimental period (e.g. SREBP-2, $F X R, P P A R \beta$ ). Except for increased expression at day 1, hepatic gene expression of cholesterol and bile acid transporters ( $A B C G 5$ and $A B C B 11$, respectively) as well as PPAR $\alpha$ seemed less influenced by SBM feeding. The individual variation in gene expression was low for most of the target genes, but CYPTA1 mRNA levels showed a high variation between SBM-fed fish.

In the DI (Fig. 4), impaired cholesterol absorption was indicated by the down-regulation of ABCG5. LXR and ASBT displayed parallel expression profiles, and were up-regulated $2-3$-fold until day 5 , and thereafter decreased reaching initial levels (day 0) at days 10-14. FXR displayed a time-dependent induction, eventually resulting in a 5.6-fold increase compared with the control levels. In concordance with intestinal inflammation, proliferating cell nuclear antigen (PCNA) mRNA levels were consistently up-regulated from day 5 .

\section{Discussion}

The reduced plasma levels of cholesterol and bile acids observed in the present study are in concordance with several previous studies ${ }^{(7,9-12,18)}$. Moreover, the present data demonstrated a similar reduction of bile acid concentration with SBM exposure in three different body compartments, i.e. intestinal lumen, blood plasma and liver. The present study suggests that the reduced cholesterol and bile acid levels observed with SBM exposure were most probably not due to impaired hepatic function since the gene expression profiles indicated that the capacity for cholesterol and bile acid synthesis was up-regulated. Most probably, it was a result of (1) impaired intestinal bile acid reabsorption and hence a reduction in the enterohepatic recovery of already synthesised bile acids, and (2) impaired intestinal cholesterol absorption and therefore decreased substrate availability for hepatic bile acid biosynthesis. The increased capacity for cholesterol and bile acid synthesis does not, however, appear to have compensated for the impaired absorption and availability of bile acids and cholesterol since plasma, liver and intestinal content levels continued to decrease during the feeding trial. The decreased hepatic glycogen/lipid deposition with increasing SBM exposure time indicated reduced energy reserves that could potentially result in reduced growth performance when salmon were fed the SBM.

Based on some recent reports, hepatic cholesterol, bile acid and fatty acid metabolism generally seem to increase when fish are fed plant products, as investigated using transcriptomic $^{(41-44)}$ and proteomic ${ }^{(45)}$ approaches. The present study is in line with these studies, indicating that hepatic capacity for cholesterol and bile acid biosynthesis was upregulated as a response to SBM inclusion. This could reflect a general need for de novo cholesterol synthesis by the animals when low levels are provided with the diet. Additionally, SBM-induced inflammation in the DI may have compromised

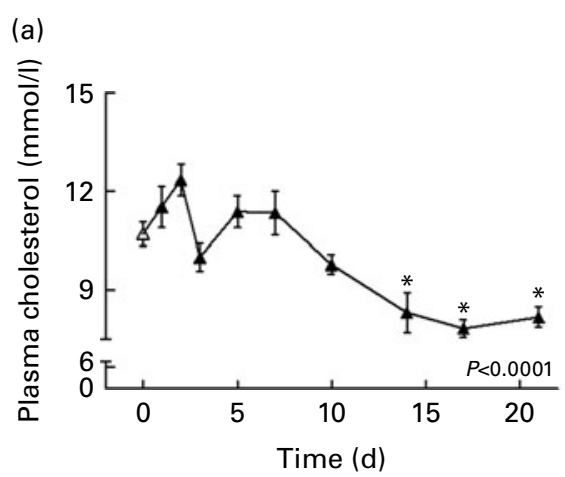

(b)

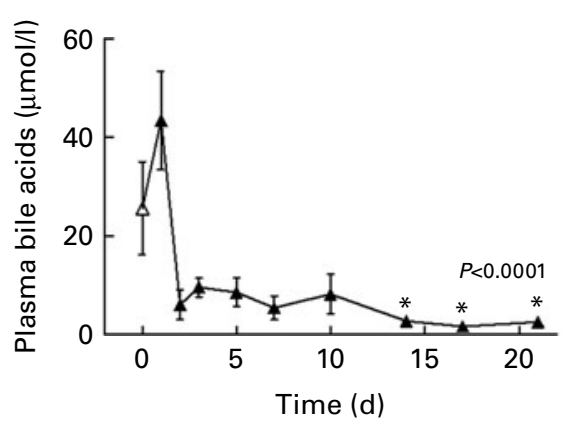

(c)

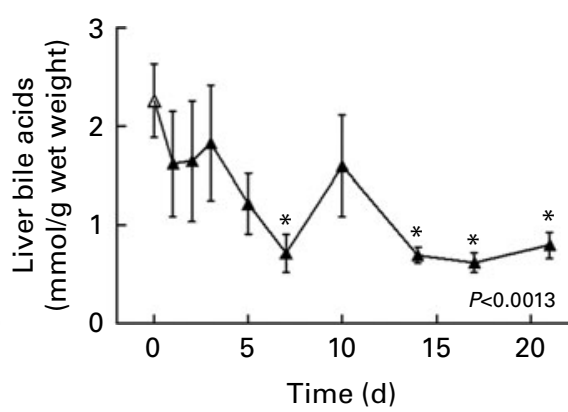

Fig. 2. Plasma levels of (a) cholesterol and (b) bile acids, and (c) hepatic levels of bile acids during $21 \mathrm{~d}$ of dietary exposure to the $20 \%$ soyabean meal (SBM). Hepatic levels of bile acids are given as $\mathrm{mmol} / \mathrm{g}$ tissue since proportions of conjugated and unconjugated bile acids in the liver are unknown. Values are means $(n 6)$, with standard errors represented by vertical bars. $P$ values for the statistical analysis (ANOVA) are given. * Mean values for SBM time points were significantly different from the control (day 0) levels. 
Table 3. Bile acid concentrations in intestinal content (mg/g DM)

(Mean values with their standard errors)

\begin{tabular}{|c|c|c|c|c|c|c|c|c|c|c|}
\hline \multirow[b]{2}{*}{ Day } & \multicolumn{2}{|c|}{ PI1 } & \multicolumn{2}{|c|}{$\mathrm{Pl} 2$} & \multicolumn{2}{|c|}{ MI } & \multicolumn{2}{|c|}{ DI1 } & \multicolumn{2}{|c|}{$\mathrm{DI} 2$} \\
\hline & Mean & SEM & Mean & SEM & Mean & SEM & Mean & SEM & Mean & SEM \\
\hline 0 & 192 & 42 & 145 & 35 & 132 & 13 & 70 & 7 & 21 & 3 \\
\hline 1 & 165 & 34 & 169 & 22 & 122 & 12 & 77 & 4 & 30 & 2 \\
\hline 2 & 169 & 36 & 127 & 28 & 110 & 18 & 66 & 17 & 20 & 6 \\
\hline 3 & 154 & 6 & 119 & 12 & 108 & 8 & 70 & 8 & 31 & 6 \\
\hline 7 & 111 & 16 & 105 & 10 & $84^{*}$ & 4 & 44 & 7 & 22 & 4 \\
\hline 14 & $41^{*}$ & 7 & $50^{\star}$ & 12 & $50^{*}$ & 6 & $26^{*}$ & 5 & 12 & 3 \\
\hline \multirow[t]{2}{*}{21} & $78^{\star}$ & 18 & 81 & 9 & $59^{*}$ & 7 & 40 & 3 & 25 & 2 \\
\hline & \multicolumn{2}{|c|}{$P<0.0001 \dagger$} & \multicolumn{2}{|c|}{$P=0.0006 \dagger$} & \multicolumn{2}{|c|}{$P<0.0001 \dagger$} & \multicolumn{2}{|c|}{$P=0.001 \dagger$} & \multicolumn{2}{|c|}{$P=0.04 \dagger$} \\
\hline
\end{tabular}

$\mathrm{PI}$, pyloric intestine; MI, mid-intestine; DI, distal intestine.

${ }^{*}$ Mean values for soyabean meal time points were significantly different from the control (day 0 ) levels.

$\dagger P$ values for the statistical analysis (ANOVA) are given.

metabolic functions such as nutrient uptake, as indicated in the present study and elsewhere ${ }^{(46,47)}$. Loss of metabolic functions could be a result of both the activation of immune responses and the dysregulation of cellular differentiation.

In mammalian systems, molecular regulation of lipid metabolism has been extensively studied, and the beneficial effects of dietary soya protein on blood lipid concentrations in a variety of animal models and human subjects have resulted in a large body of literature on this topic (reviewed in Potter ${ }^{(48)}$ and Torres et al. $\left.{ }^{(49)}\right)$. To summarise the findings from mammalian systems, dietary soya protein generally increases faecal excretion of bile acids, which in turn induces a shift in hepatic cholesterol metabolism. Cholesterol biosynthesis increases to provide cholesterol for increased bile acid biosynthesis, and the net result is increased removal of cholesterol from the blood and thereby decreased blood cholesterol concentrations ${ }^{(48)}$. The causative agent(s) for the observed differences in blood lipid levels with increased plant materials in diets have, however, not been identified. Proposed explanations include the difference in amino acid profile ${ }^{(49)}$ and/ or the influence of plant anti-nutrients, particularly fibres, saponins and isoflavones, on intestinal bile acid and cholesterol absorption, as well as general lipid metabolism ${ }^{(33,34,36,48)}$.

The present study reveals novel information on the regulation of cholesterol and bile acid metabolism in a piscine model. A summary of the proposed regulation is presented in Fig. 5. As mentioned above, the present data indicate that the capacity for cholesterol biosynthesis was up-regulated in SBM-fed fish as a response to the reduced plasma cholesterol levels. In mammals, the committed step in cholesterol biosynthesis is the synthesis of mevalonate by HMGCR, and HMGCR mRNA transcription is controlled by SREBP ${ }^{(50,51)}$. Thus, it is believed that liver SREBP, especially SREBP-2, are activated in response to the reduction in hepatic cholesterol content ${ }^{(52)}$. SREBP and HMGCR proteins are bound in the endoplasmic reticulum membrane, and high intracellular sterol levels will inhibit SREBP cleavage, degrade HMGCR and thereby terminate sterol synthesis. At low sterol levels, SREBP are cleaved, translocated to the nucleus and will up-regulate genes involved in sterol metabolism ${ }^{(51)}$. Generally, SREBP-1 regulates genes required for lipogenesis, whereas SREBP-2 regulates genes required for cholesterol synthesis and transport, including $H M G C R$ and $A B C G 5^{(50,53)}$. SREBP-1 and -2 were recently characterised in salmon ${ }^{(38)}$. In accordance with mammalian studies, SREBP-2 was shown to be the main regulator involved in the up-regulation of cholesterol biosynthetic pathways in salmon fed diets containing vegetable oil ${ }^{(42)}$. Additionally, HMGCR mRNA has been reported to be up-regulated in European sea bass (Dicentrarchus labrax) and yellowtail (Seriola quinqueradiata) fed non-FM diets ${ }^{(44,54)}$. The present study is in line with these previous reports, showing the upregulation of SREBP-1 and -2 as well as HMGCR in fish fed SBM. In line with reports identifying SREBP-2 as the main regulator for sterol metabolism, SREBP-2 showed a stronger and more consistent response to the SBM diet when compared with SREBP-1. However, whether the observed up-regulation of SREBP and HMGCR was due to decreased hepatic cholesterol availability, or if the soya anti-nutrients affected hepatic cholesterol metabolism directly, as observed previously in mammalian cell models ${ }^{(34)}$, remains to be elucidated.

Primary bile acids are synthesised from cholesterol exclusively in the liver, and the classical pathway mediated by the rate-limiting enzyme CYP7A1 is thought to be the major contributor to bile acid synthesis in humans ${ }^{(55)}$. Reflecting that bile acid synthesis is a major route for cholesterol elimination, CYP7A1 is down-regulated by FXR when plasma cholesterol levels are low, but up-regulated by LXR when cholesterol levels are high ${ }^{(30)}$. LXR and FXR are activated by oxysterols and bile acids, respectively ${ }^{(56)}$, and will often oppose each other's actions in the enterohepatic system by diametrically regulating expression of the same target genes, such as $C Y P 7 A 1$. LXR and FXR may also induce positive autoregulation $^{(30)}$. The present data indicate that a similar regulatory expression pattern of LXR and FXR may be present in salmon. Both in the liver and DI, LXR was up-regulated at early time points of SBM inclusion (days 1-5), whereas a down-regulation from approximately day 7 and throughout the experimental period was accompanied by an up-regulation of FXR. A recent mechanistic study using an established salmon cell line (SHK-1) also reported LXR regulation of key lipid metabolism genes, and LXR were found to be up-regulated by cholesterol treatment ${ }^{(38)}$. In contrast, to our knowledge, no studies have investigated $C Y P 7 A 1$ gene expression in salmon. In the present study, CYP7A1 mRNA levels showed 

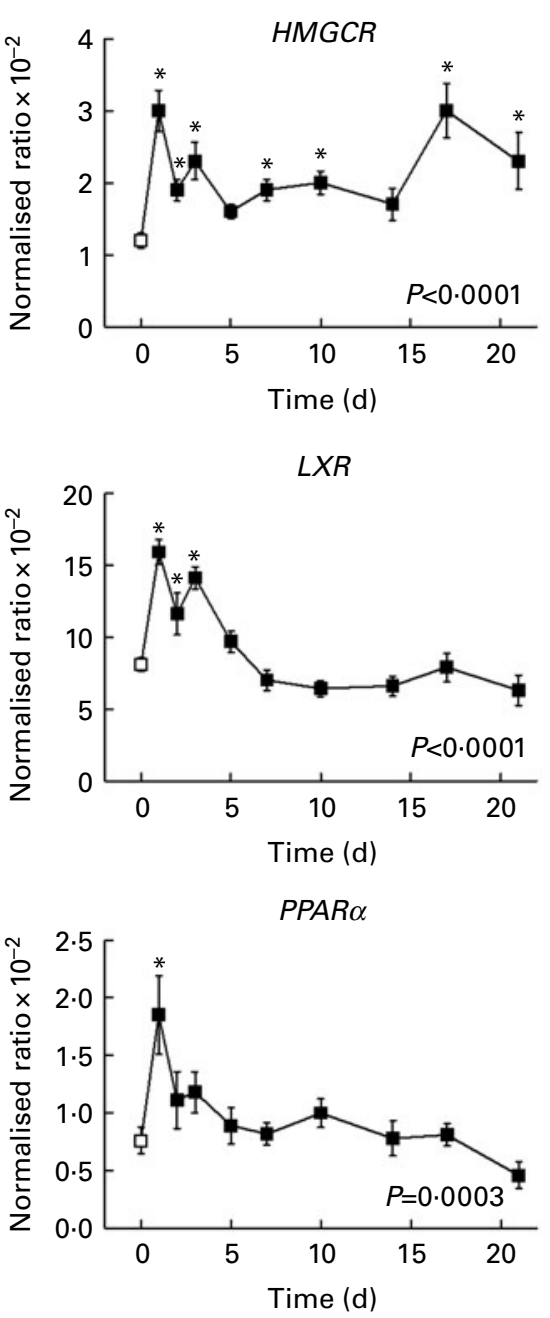
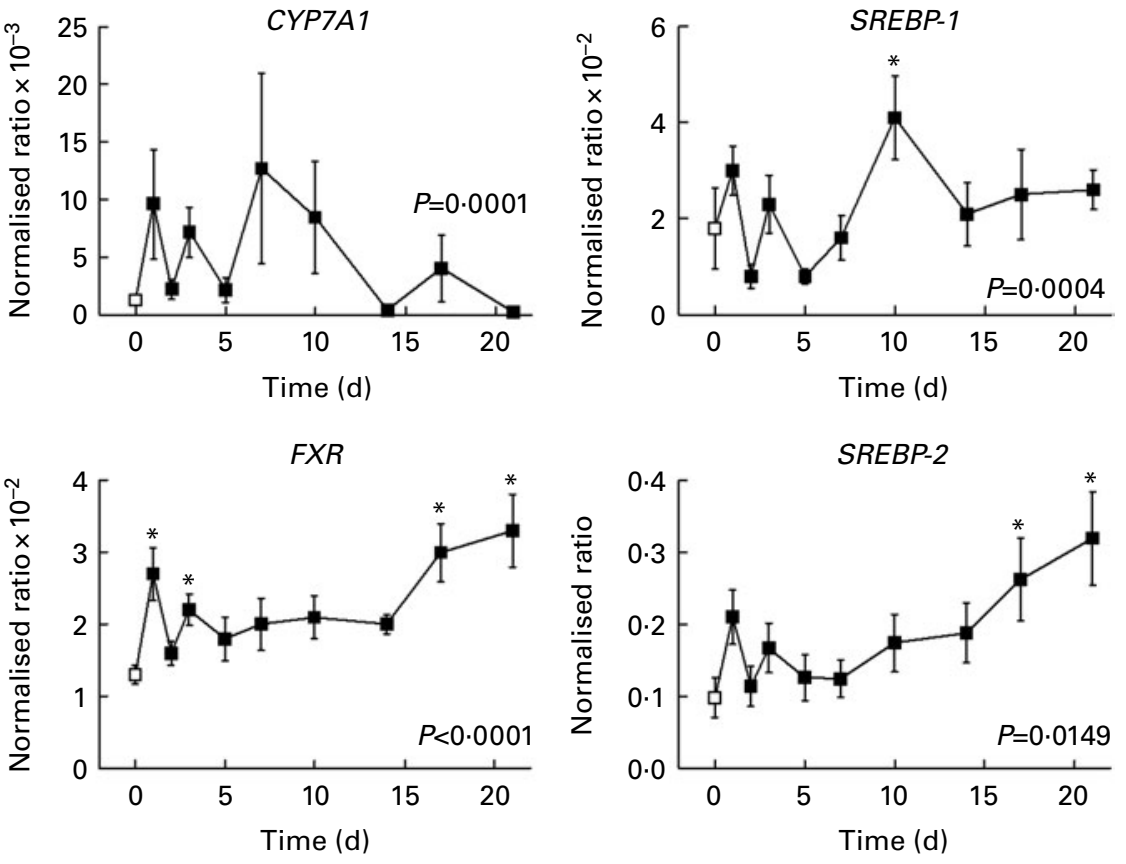

PPAR $\beta$
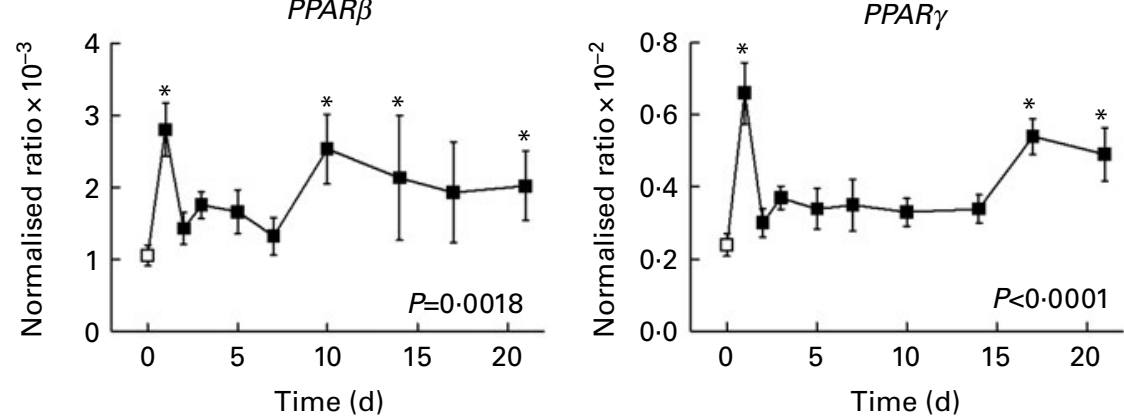
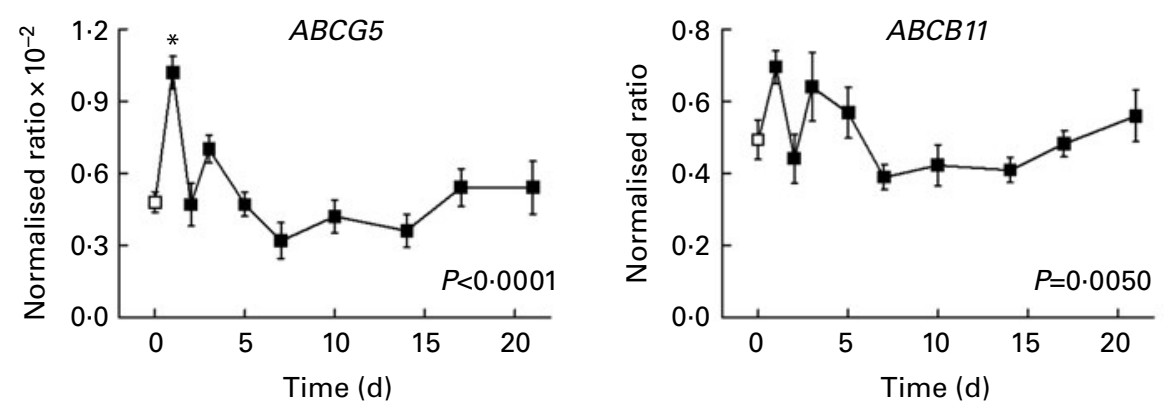

Fig. 3. Hepatic gene expression of 3-hydroxy-3-methyl-glutaryl-CoA reductase (HMGCR), cytochrome P4507A1 (CYP7A1), sterol regulatory element binding proteins (SREBP-1 and SREBP-2), liver X receptor ( $L X R)$, farnesoid $\mathrm{X}$ receptor (FXR), PPAR isoforms (PPAR $\alpha$ /PPAR $/$ /PPAR $\gamma$ ) and ATP binding cassette G5 and B11 (ABCG5 and $A B C B 11)$ during $21 \mathrm{~d}$ of dietary exposure to the $20 \%$ soyabean meal (SBM). Values are means $(n 8)$, with standard errors represented by vertical bars. $P$ values for the statistical analysis (ANOVA) are given. ${ }^{*}$ Mean values for SBM time points were significantly different from the control (day 0 ) levels.

high variation, and some individuals seemed to respond to the SBM diet, whereas others remained unaffected. This might be a result of the dual actions of CYP7A1 (cholesterol catabolism and bile acid synthesis) in a system, which showed depletion of both cholesterol and bile acids. Additionally, the alternative bile acid synthesis pathway, initiated by CYP27A1, may have contributed to overall bile acid biosynthesis ${ }^{(55)}$.
In addition to SREBP and LXR/FXR, PPAR isoforms are also important regulators of lipid homeostasis. Because of their key roles in regulating fatty acid $\beta$-oxidation (catabolism) as well as lipogenesis and fat accumulation, PPAR research has received considerable attention in aquaculture nutritional studies $^{(57-59)}$. Generally, PPAR are activated by fatty acids and eicosanoids ${ }^{(60)}$, but interestingly, both PPAR $\alpha$ and 

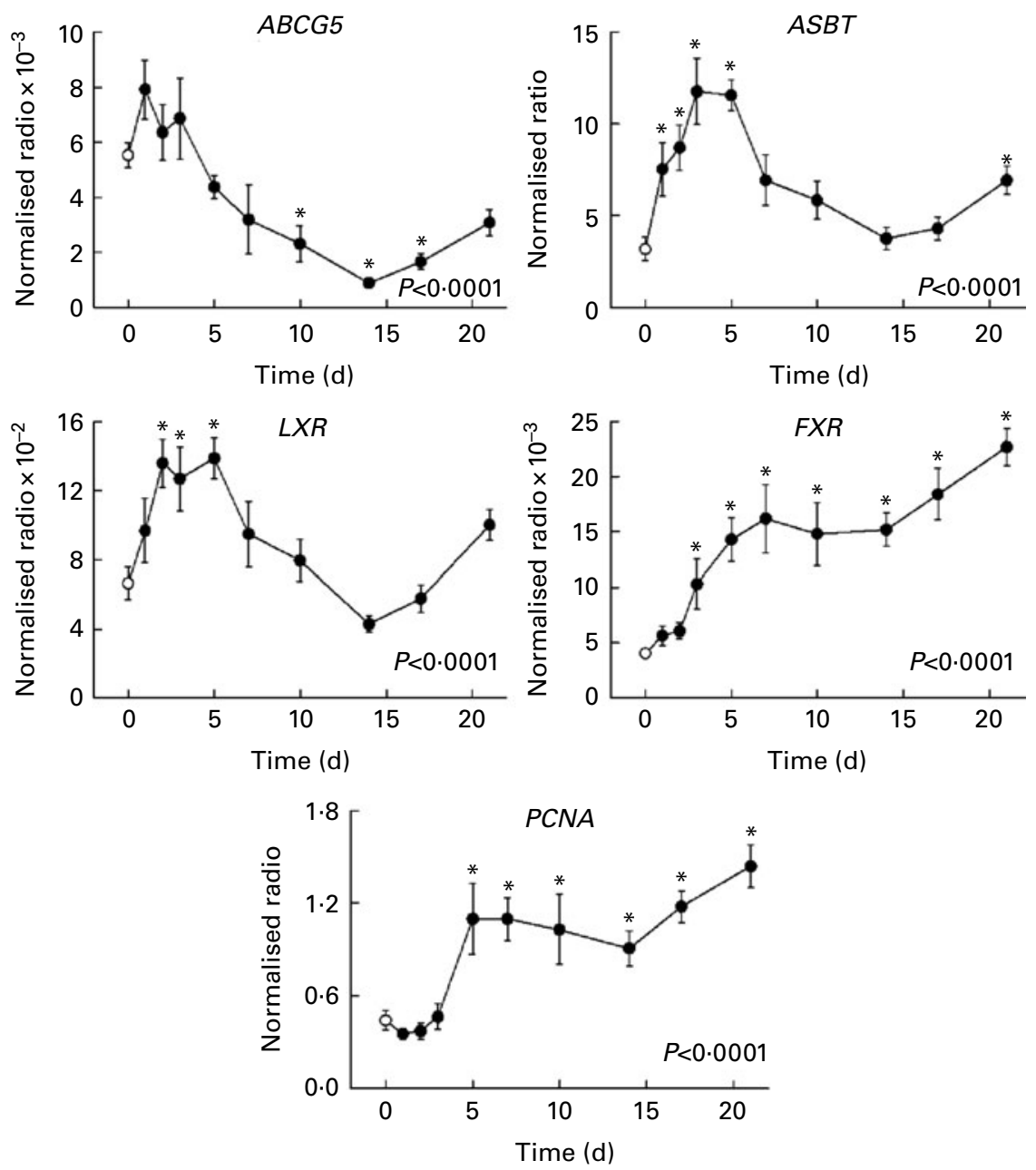

Fig. 4. Distal intestinal gene expression of ATP binding cassette G5 (ABCG5), apical sodium-dependent bile acid transporter (ASBT), liver X receptor ( $L X R)$, farnesoid $\mathrm{X}$ receptor $(F X R)$ and proliferating cell nuclear antigen (PCNA) during $21 \mathrm{~d}$ of dietary exposure to the $20 \%$ soyabean meal (SBM). Values are means $(n 8)$, with standard errors represented by vertical bars. $P$ values for the statistical analysis (ANOVA) are given. * Mean values for SBM time points were significantly different from the control (day 0 ) levels.

PPAR $\gamma$ can be activated by soya isoflavones ${ }^{(33)}$. Although evidence remains elusive, PPAR $\alpha$ has been associated with the regulation of bile acid synthesis in mammalian models, possibly by fibrate PPAR $\alpha$-dependent repression of CYP7A1 and bile acid transporters ${ }^{55,61)}$. Moreover, hepatic PPAR $\alpha$ mRNA levels are up-regulated by dietary soya proteins in rats ${ }^{(49)}$. PPAR isoforms have also been shown to interact and crosstalk with other nuclear receptors such as SREBP, LXR and FXR (reviewed in Li \& Chiang ${ }^{(55)}$ ). In the present study, $P P A R \alpha$ gene expression remained unaffected by SBM inclusion, whereas $P P A R \beta$ and PPAR $\gamma$ were up-regulated, and may be directly involved in the transcription regulation of hepatic cholesterol and bile acid metabolism. Nevertheless, considering the ability of PPAR to regulate a vast number of cellular signalling pathways, more studies are needed to explain PPAR regulatory roles in hepatic sterol metabolism in salmon. A general feature of hepatic gene expression was the relatively subtle changes after SBM inclusion (2-3-fold) when compared with the control diet. This is a common methodological challenge in nutritional studies, where animal physiology and metabolism can be markedly affected by even small changes in gene expression (see Morais et al. ${ }^{(62)}$ and references therein).

In addition to enzymes catalysing biosynthesis, the enterohepatic circulation of cholesterol and bile acids is dependent on the action of several hepatic and intestinal membrane transporters ${ }^{(20,63)}$. In the liver, the ATP-binding cassettes ABCG5 (which forms a heterodimer with ABCG8) and ABCB11 mediate efflux of cholesterol and bile acids, respectively, from the liver into the bile. Consequently, $A B C G 5 \mathrm{mRNA}$ expression is positively regulated by LXR, whereas $A B C B 11$ mRNA expression is positively regulated by $\mathrm{FXR}^{(60)}$. In the present study, ABCG5 and LXR displayed similar gene expression profiles both in the liver and DI. Hepatic ABCG5 mRNA levels were, however, by and large unaffected by SBM inclusion, whereas SBM produced a strong down-regulation of $A B C G 5$ in the DI. In mammals, the intestinal $\mathrm{ABCG} / \mathrm{G} 8$ heterodimer is situated on the apical membrane of epithelial cells, where it functions to transport intracellular cholesterol into the gut lumen, thereby limiting plant sterol 


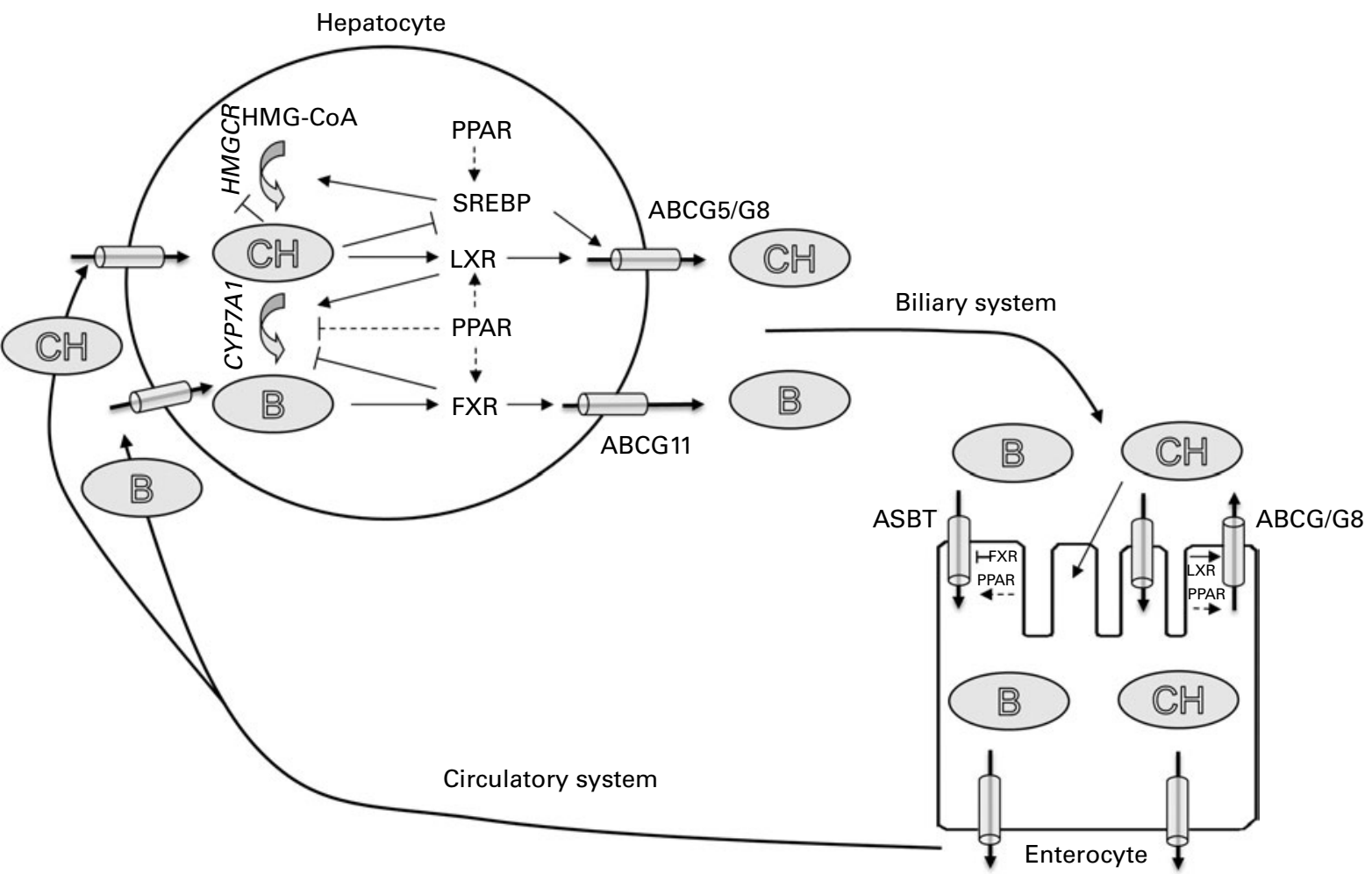

Fig. 5. Proposed molecular regulation of cholesterol $(\mathrm{CH})$ and bile acid $(\mathrm{B})$ metabolism based on data from the present study and previous studies in fish and mammalian species. $\mathrm{CH}$ and primary $\mathrm{B}$ are major constituents of bile that are synthesised in the liver and released into the biliary duct via specific membrane transporters (ABCG5/G8 and ABCB11). Bile is stored in the gallbladder and released into the gut upon ingestion of feed. Bile acids are reabsorbed by enterocytes from the gut lumen via specific apical membrane transporters (ASBT). $\mathrm{CH}$ is absorbed by diffusion or active transport. Some of the absorbed $\mathrm{CH}$ is pumped out of the enterocyte by $A B C G 5 / G 8$, back into the intestinal lumen for elimination from the body. $\mathrm{CH}$ and $\mathrm{B}$ are subsequently shuffled out of the enterocytes at the basolateral membrane, transported via the circulatory system and reabsorbed by the liver. In the hepatocytes, sterol regulatory element binding protein (SREBP) upregulate genes for $\mathrm{CH}$ synthesis (3-hydroxy-3-methyl-glutaryl-CoA reductase (HMGCR)) and transport (ABCG5/G8). High sterol levels will inhibit SREBP and degrade HMGCR and thereby terminate sterol synthesis. Liver X receptor (LXR) is activated by sterols, and up-regulate genes for $\mathrm{CH}$ catabolism (cytochrome P4507A1 (CYP7A1)) and transport (ABCG5/G8). Farnesoid $X$ receptor (FXR) is activated by bile acids, and decrease intracellular bile acid levels by down-regulation of CYP7A1 and up-regulation of ABCB11 in the liver, as well as down-regulation of ASBT in enterocytes. PPAR are associated with the regulation of $\mathrm{CH}$ and $\mathrm{B}$ metabolism, possibly by PPAR $\alpha$-dependent repression of CYP7A1. PPAR have also been shown to interact and crosstalk with SREBP, LXR and FXR. $\rightarrow$ Activation; - inhibition; --.-, possible interaction.

and cholesterol uptake by the gut ${ }^{(63)}$. The reason for the apparent down-regulation of $A B C G 5$ mRNA expression in the DI is not clear, but it is most probably a result of SBM-induced intestinal inflammation impairing enterocyte maturation and thereby reducing the concentration of brush-border proteins. Accordingly, decreased nutrient absorption and increased permeability of distal intestinal epithelium have been observed after SBM inclusion in salmon feed, directly by the actions of soya anti-nutrients or indirectly by increased cellular proliferation $^{(46,64,65)}$. Similarly, hepatic $A B C B 11$ mRNA levels remained unaffected by SBM inclusion, whereas distal intestinal mRNA levels of $A S B T$ (gene symbol SLC1OA2) were initially up-regulated until day 5 of SBM feeding. ASBT is responsible for the intestinal uptake of bile acids across the enterocyte brush-border membrane ${ }^{(66)}$, and it should be expected that ASBT is negatively regulated by FXR, thereby limiting bile acid reabsorption from the gut. Thus, the down-regulation of ASBT after 10-21 d of SBM feeding compared with early time points (days 3-5) could be a response to the consistent upregulation of FXR. However, a number of cytokines, hormones and sterols are known to regulate $A S B T$ gene expression ${ }^{(20)}$, so the observed modulation in $A S B T$ mRNA expression after SBM inclusion is most probably not a result of altered epithelial bile acid levels alone. Increased distal intestinal FXR mRNA expression may also be a direct result of the inflammation, as it has recently been demonstrated that FXR inhibits inflammation and preserves the intestinal barrier in gastrointestinal diseases ${ }^{(56,67)}$

Finally, the present data are in concordance with numerous reports showing that inclusion of $>10 \%$ SBM produces enteropathy in the DI of salmonids ${ }^{(2,3,8)}$. Previously, bile acid deficiency has been implicated as a possible cause of SBM-induced enteritis in rainbow trout, since dietary supplementation with bile salts appeared to ameliorate the condition $^{(10)}$. However, the present data indicate that bile acids were amply present in the DI as the onset of morphological signs of inflammation became evident following initial SBM exposure. Bile acids appear to become in short supply following a week or more of exposure. Therefore, other mechanisms are most probably involved in the bile salt alleviation of SBM-induced inflammation in trout. Whether bile salt supplementation has a similar effect in SBM-fed salmon 
remains to be elucidated. The increased distal intestinal gene expression of PCNA confirmed earlier reports of PCNA translational up-regulation using immunohistochemistry ${ }^{(64,68)}$. However, this is the first study that reports PCNA gene expression profiling during the development of the enteritis, demonstrating that PCNA may be used as a sensitive biomarker for the inflammation, not only at the translational but also at the transcriptional level.

To summarise, data from the present study suggest that hepatic metabolism of cholesterol and bile acids remains functional throughout a $21 \mathrm{~d} 20 \%$ SBM feeding trial, as indicated by hepatic gene expression profiling and histopathology. Hepatic gene expression profiles indicated that the capacity for cholesterol and bile acid synthesis was up-regulated, whereas distal intestinal gene expression indicated impaired cholesterol and bile acid absorption, probably occurring as a direct result of functional loss due to inflammation. However, increased hepatic synthesis of sterols did not seem to compensate fully for distal intestinal dysfunction, since plasma cholesterol and bile acid levels continued to decrease throughout the feeding trial.

\section{Acknowledgements}

This study was financially supported by The Research Council of Norway's Centre of Excellence Aquaculture Protein Centre (APC; grant no. 145949/120). Thanks are due to the animal technicians at Nofima Marin at Sunndalsøra for excellent fish care and management and to the laboratory technicians at Nofima Marin and the Gut and Health Group of the Aquaculture Protein Centre for skillful performance of all the necessary analyses. The authors' contributions were as follows: T. M. K. performed the gene expression work and wrote the manuscript; J. G. performed the histopathology and reviewed the manuscript. A. M. B. and A. K. designed and conducted the feeding trial and reviewed the manuscript. The authors declare that there are no conflicts of interest.

\section{References}

1. Gatlin DM, Barrows FT, Brown P, et al. (2007) Expanding the utilization of sustainable plant products in aquafeeds: a review. Aquac Res 38, 551-579.

2. van den Ingh TSGA, Krogdahl $\AA$, Olli JJ, et al. (1991) Effects of soybean-containing diets on the proximal and distal intestine in Atlantic Salmon (Salmo salar): a morphological study. Aquaculture 94, 297-305.

3. Baeverfjord G \& Krogdahl ^ (1996) Development and regression of soybean meal induced enteritis in Atlantic salmon, Salmo salar L., distal intestine: a comparison with the intestines of fasted fish. J Fish Dis 19, 375-387.

4. van den Ingh TSGA, Olli JJ \& Krogdahl A (1996) Alcoholsoluble components in soybeans cause morphological changes in the distal intestine of Atlantic salmon, Salmo salar L. J Fish Dis 19, 47-53.

5. Uran PA, Goncalves AA, Taverne-Thiele JJ, et al. (2008) Soybean meal induces intestinal inflammation in common carp (Cyprinus carpio L.). Fish Shellfish Immunol 25, 751-760.

6. Olli JJ \& Krogdahl A (1994) Nutritive value of 4 soybean products as protein sources in diets for rainbow trout (Oncor- bynchus mykiss, Walbaum) reared in fresh-water. Acta Agricult Scand A - Anim Sci 44, 185-192.

7. Kaushik SJ, Cravedi JP, Lalles JP, et al. (1995) Partial or total replacement of fish meal by soybean protein on growth, protein utilization, potential estrogenic or antigenic effects, cholesterolemia and flesh quality in rainbow trout, Oncorhynchus mykiss. Aquaculture 133, 257-274.

8. Krogdahl ^, Bakke-McKellep AM \& Baeverfjord G (2003) Effects of graded levels of standard soybean meal on intestinal structure, mucosal enzyme activities, and pancreatic response in Atlantic salmon (Salmo salar L.). Aquaculture Nutr 9, 361-371.

9. Romarheim OH, Skrede A, Gao YL, et al. (2006) Comparison of white flakes and toasted soybean meal partly replacing fish meal as protein source in extruded feed for rainbow trout (Oncorbynchus mykiss). Aquaculture 256, 354-364.

10. Yamamoto T, Suzuki N, Furuita H, et al. (2007) Supplemental effect of bile salts to soybean meal-based diet on growth and feed utilization of rainbow trout Oncorhynchus mykiss. Fish Sci 73, 123-131.

11. Romarheim OH, Skrede A, Penn M, et al. (2008) Lipid digestibility, bile drainage and development of morphological intestinal changes in rainbow trout (Oncorbynchus mykiss) fed diets containing defatted soybean meal. Aquaculture 274, 329-338.

12. Sørensen M, Penn M, El-Mowafi A, et al. (2011) Effect of stachyose, raffinose and soya-saponins supplementation on nutrient digestibility, digestive enzymes, gut morphology and growth performance in Atlantic salmon (Salmo salar, L). Aquaculture 314, 145-152.

13. Regost C, Arzel J \& Kaushik SJ (1999) Partial or total replacement of fish meal by corn gluten meal in diet for turbot (Psetta maxima). Aquaculture 180, 99-117.

14. Gomez-Requeni $\mathrm{P}$, Mingarro $\mathrm{M}$, Calduch-Giner JA, et al. (2004) Protein growth performance, amino acid utilisation and somatotropic axis responsiveness to fish meal replacement by plant protein sources in gilthead sea bream (Sparus aurata). Aquaculture 232, 493-510.

15. Sitja-Bobadilla A, Pena-Llopis S, Gomez-Requeni $\mathrm{P}$, et al. (2005) Effect of fish meal replacement by plant protein sources on non-specific defence mechanisms and oxidative stress in gilthead sea bream (Sparus aurata). Aquaculture 249, 387-400.

16. Hansen AC, Rosenlund G, Karlsen O, et al. (2007) Total replacement of fish meal with plant proteins in diets for Atlantic cod (Gadus morhua L.) I - effects on growth and protein retention. Aquaculture 272, 599-611.

17. Lim SJ \& Lee KJ (2009) Partial replacement of fish meal by cottonseed meal and soybean meal with iron and phytase supplementation for parrot fish Oplegnathus fasciatus. Aquaculture 290, 283-289.

18. Yun BA, Mai KS, Zhang WB, et al. (2011) Effects of dietary cholesterol on growth performance, feed intake and cholesterol metabolism in juvenile turbot (Scophthalmus maximus L.) fed high plant protein diets. Aquaculture 319, 105-110.

19. Hofmann AF \& Hagey LR (2008) Bile acids: chemistry, pathochemistry, biology, pathobiology, and therapeutics. Cell Mol Life Sci 65, 2461-2483.

20. Dawson PA, Lan T \& Rao A (2009) Bile acid transporters. J Lipid Res 50, 2340-2357.

21. Hylemon PB, Zhou HP, Pandak WM, et al. (2009) Bile acids as regulatory molecules. J Lipid Res 50, 1509-1520.

22. Fiorucci S, Cipriani S, Mencarelli A, et al. (2010) Counterregulatory role of bile acid activated receptors in immunity and inflammation. Cur Mol Med 10, 579-595. 
23. D'Aldebert E, Mve MJBB, Mergey M, et al. (2009) Bile salts control the antimicrobial peptide cathelicidin through nuclear receptors in the human biliary epithelium. Gastroenterol 136, 1435-1443

24. Bajor A, Gillberg PG \& Abrahamsson H (2010) Bile acids: short and long term effects in the intestine. Scand J Gastroenterol 45, 645-664.

25. Schlottmann K, Wachs FP, Krieg RC, et al. (2000) Characterization of bile salt-induced apoptosis in colon cancer cell lines. Cancer Res 60, 4270-4276.

26. Wachs FP, Krieg RC, Rodrigues CMP, et al. (2005) Bile saltinduced apoptosis in human colon cancer cell lines involves the mitochondrial transmembrane potential but not the CD95 (Fas/Apo-1) receptor. Int J Col Dis 20, 103-113.

27. Cronin J, Williams L, McAdam E, et al. (2010) The role of secondary bile acids in neoplastic development in the oesophagus. Biochem Soc Trans 38, 337-342.

28. Park JS, Yoo DH, Lee IJ, et al. (2010) Therapeutic effect of whole bear bile and its components against croton oilinduced rectal inflammation in rats. Biomol Therap 18, 83-91.

29. Claudel T, Zollner G, Wagner M, et al. (2011) Role of nuclear receptors for bile acid metabolism, bile secretion, cholestasis, and gallstone disease. Biochim Biophys Acta - Mol Bas Dis 1812, 867-878.

30. Kalaany NY \& Mangelsdorf DJ (2006) LXRs and FXR: the yin and yang of cholesterol and fat metabolism. Ann Rev Physiol 68, 159-191.

31. Francis G, Makkar HPS \& Becker K (2001) Antinutritional factors present in plant-derived alternate fish feed ingredients and their effects in fish. Aquaculture 199, 197-227.

32. Krogdahl $\AA$, Penn M, Thorsen J, et al. (2010) Important antinutrients in plant feedstuffs for aquaculture: an update on recent findings regarding responses in salmonids. Aquac Res 41, 333-344.

33. Ricketts ML, Moore DD, Banz WJ, et al. (2005) Molecular mechanisms of action of the soy isoflavones includes activation of promiscuous nuclear receptors. A review. J Nutr Biochem 16, 321-330.

34. Mullen E, Brown RM, Osborne TF, et al. (2004) Soy isoflavones affect sterol regulatory element binding proteins (SREBPs) and SREBP-regulated genes in HepG2 cells. J Nutr 134, 2942-2947.

35. Francis G, Kerem Z, Makkar HPS, et al. (2002) The biological action of saponins in animal systems: a review. BrJ Nutr $\mathbf{8 8}$, 587-605.

36. Messina MJ (1999) Legumes and soybeans: overview of their nutritional profiles and health effects. Am J Clin Nut $\mathbf{7 0}$, 439S-450S.

37. Kortner TM, Valen EC, Kortner H, et al. (2011) Candidate reference genes for quantitative real-time PCR (qPCR) assays during development of a diet-related enteropathy in Atlantic salmon (Salmo salar L.) and the potential pitfalls of uncritical use of normalization software tools. Aquaculture 318, 355-363.

38. Minghetti M, Leaver MJ \& Tocher DR (2011) Transcriptional control mechanisms of genes of lipid and fatty acid metabolism in the Atlantic salmon (Salmo salar L.) established cell line, SHK-1. Biochim Biophys Acta 1811, 194-202.

39. Zaja R, Munic V, Klobucar RS, et al. (2008) Cloning and molecular characterization of apical efflux transporters (ABCB1, $\mathrm{ABCB} 11$ and $\mathrm{ABCC} 2$ ) in rainbow trout (Oncorbynchus mykiss) hepatocytes. Aquat Toxicol 90, 322-332.

40. Muller PY, Janovjak H, Miserez AR, et al. (2002) Processing of gene expression data generated by quantitative real-time RT-PCR. Biotechniques 32, 1372-1374, 1376, 1378, 1379.
41. Jordal AEO, Torstensen BE, Tsoi S, et al. (2005) Dietary rapeseed oil affects the expression of genes involved in hepatic lipid metabolism in Atlantic salmon (Salmo salar L.). J Nutr 135, 2355-2361.

42. Leaver MJ, Villeneuve LAN, Obach A, et al. (2008) Functional genomics reveals increases in cholesterol biosynthetic genes and highly unsaturated fatty acid biosynthesis after dietary substitution of fish oil with vegetable oils in Atlantic salmon (Salmo salar). BMC Genom 9, 299.

43. Panserat S, Hortopan GA, Plagnes-Juan E, et al. (2009) Differential gene expression after total replacement of dietary fish meal and fish oil by plant products in rainbow trout (Oncorbynchus mykiss) liver. Aquaculture 294, $123-131$

44. Geay F, Ferraresso S, Zambonino-Infante JL, et al. (2011) Effects of the total replacement of fish-based diet with plant-based diet on the hepatic transcriptome of two European sea bass (Dicentrarchus labrax) half-sibfamilies showing different growth rates with the plant-based diet. $B M C$ Genom 12, 522 .

45. Vilhelmsson OT, Martin SAM, Medale F, et al. (2004) Dietary plant-protein substitution affects hepatic metabolism in rainbow trout (Oncorbynchus mykiss). Br J Nutr 92, 71-80.

46. Nordrum S, Bakke-McKellep AM, Krogdahl ^, et al. (2000) Effects of soybean meal and salinity on intestinal transport of nutrients in Atlantic salmon (Salmo salar L.) and rainbow trout (Oncorbynchus mykiss). Comp Biochem Physiol B Biochem Mol Biol 125, 317-335.

47. Uran PA, Aydin R, Schrama JW, et al. (2008) Soybean mealinduced uptake block in Atlantic salmon Salmo salar distal enterocytes. J Fish Biol 73, 2571-2579.

48. Potter SM (1995) Overview of proposed mechanisms for the hypocholesterolemic effect of soy. J Nutr 125, S606-S611.

49. Torres N, Torre-Villalvazo I \& Tovar AR (2006) Regulation of lipid metabolism by diseases mediated soy protein and its implication in by lipid disorders. J Nutr Biochem 17 365-373

50. Brown MS \& Goldstein JL (1997) The SREBP pathway: regulation of cholesterol metabolism by proteolysis of a membrane-bound transcription factor. Cell 89, 331-340.

51. Goldstein JL, DeBose-Boyd RA \& Brown MS (2006) Protein sensors for membrane sterols. Cell 124, 35-46.

52. Sato R (2010) Sterol metabolism and SREBP activation. Arch Biochem Biophys 501, 177-181.

53. Maxwell KN, Soccio RE, Duncan EM, et al. (2003) Novel putative SREBP and LXR target genes identified by microarray analysis in liver of cholesterol-fed mice. J Lipid Res $\mathbf{4 4}$, 2109-2119.

54. Maita M, Maekawa J, Satoh K, et al. (2006) Disease resistance and hypocholesterolemia in yellowtail Seriola quinqueradiata fed a non-fishmeal diet. Fish Sci 72, 513-519.

55. Li TG \& Chiang JYL (2009) Regulation of bile acid and cholesterol metabolism by PPARs. Ppar Res 501739.

56. Gadaleta RM, van Mil SWC, Oldenburg B, et al. (2010) Bile acids and their nuclear receptor FXR: relevance for hepatobiliary and gastrointestinal disease. Biochim Biophys Acta Mol Cell Biol Lipids 1801, 683-692.

57. Ruyter B, Andersen O, Dehli A, et al. (1997) Peroxisome proliferator activated receptors in Atlantic salmon (Salmo salar): effects on PPAR transcription and acyl-CoA oxidase activity in hepatocytes by peroxisome proliferators and fatty acids. Biochim Biophys Acta - Lipids Lipid Metabol 1348, $331-338$

58. Leaver MJ, Ezaz MT, Fontagne S, et al. (2007) Multiple peroxisome proliferator-activated receptor beta subtypes from 
Atlantic salmon (Salmo salar). J Mol Endocrinol 38 391-400.

59. Leaver MJ, Bautista JM, Bjornsson BT, et al. (2008) Towards fish lipid nutrigenomics: current state and prospects for finfish aquaculture. Rev Fish Sci 16, 73-94.

60. Chawla A, Repa JJ, Evans RM, et al. (2001) Nuclear receptors and lipid physiology: opening the X-files. Science 294, 1866-1870.

61. Hunt MC, Yang YZ, Eggertsen G, et al. (2000) The peroxisome proliferator-activated receptor alpha (PPAR alpha) regulates bile acid biosynthesis. J Biol Chem 275, 28947-28953.

62. Morais S, Pratoomyot J, Taggart JB, et al. (2011) Genotypespecific responses in Atlantic salmon (Salmo salar) subject to dietary fish oil replacement by vegetable oil: a liver transcriptomic analysis. BMC Genomics 12, 255.

63. von Bergmann K, Sudhop T \& Lutjohann D (2005) Cholesterol and plant sterol absorption: recent insights. Am J Cardiol 96, 10D-14D.
64. Sanden M, Berntssen MHG, Krogdahl ^, et al. (2005) An examination of the intestinal tract of Atlantic salmon, Salmo salar L., parr fed different varieties of soy and maize. J Fish Dis 28, 317-330.

65. Knudsen D, Jutfelt F, Sundh H, et al. (2008) Dietary soya saponins increase gut permeability and play a key role in the onset of soyabean-induced enteritis in Atlantic salmon (Salmo salar L.). Br J Nutr 100, 120-129.

66. Hagenbuch B \& Dawson P (2004) The sodium bile salt cotransport family SLC10. Pflugers Arch Eur J Physiol 447, 566-570.

67. Gadaleta RM, van Erpecum KJ, Oldenburg B, et al. (2011) Farnesoid $\mathrm{X}$ receptor activation inhibits inflammation and preserves the intestinal barrier in inflammatory bowel disease. Gut 60, 463-472.

68. Bakke-McKellep AM, Penn MH, Salas PM, et al. (2007) Effects of dietary soyabean meal, inulin and oxytetracycline on intestinal microbiota and epithelial cell stress, apoptosis and proliferation in the teleost Atlantic salmon (Salmo salar L.). Br J Nutr 97, 699-713. 